\title{
Fasting for Laboratory Tests Poses a High Risk of Hypoglycemia in Patients with Diabetes: A Pilot Prevalence Study in Clinical Practice
}

\author{
Saleh Aldasouqi1 ${ }^{*}$, William Corser ${ }^{2}$, George S. Abela ${ }^{3}$, Samia Mora $^{4}$, Keren Shahar ${ }^{5}$, \\ Preethi Krishnan6, Farhan Bhatti ${ }^{7}$, Andrew Hsu ${ }^{8}$, Dane Gruenebaum ${ }^{9}$ \\ ${ }^{1}$ Division of Endocrinology, Department of Medicine, Michigan State University (MSU) College of Human Medicine (CHM), \\ East Lansing, MI and Sparrow Health System, Lansing, MI, USA \\ ${ }^{2}$ Michigan State University Statewide Campus System, College of Osteopathic Medicine, East Lansing, MI, USA \\ ${ }^{3}$ Division of Cardiology, Department of Medicine, MSU-CHM, East Lansing, MI, USA \\ ${ }^{4}$ Division of Preventive Medicine, Department of Medicine, Brigham and Women's Hospital and Harvard Medical School, Boston, MA, USA \\ ${ }^{5}$ Internal Medicine Residency Program, Department of Medicine, MSU-CHM, East Lansing, MI and Sparrow Health System, Lansing, MI, USA \\ ${ }^{6}$ Family Medicine Residency Program, Department of Family Medicine, MSU-CHM, East Lansing, MI and Sparrow Health System, \\ Lansing, MI, USA \\ ${ }^{7}$ Care Free Clinic, Lansing, MI, USA \\ ${ }^{8} \mathrm{MSU}$ College of Science, East Lansing, MI, USA \\ ${ }^{9}$ Corpus Christi Medical Center, Corpus Christi, TX, USA \\ Email: *saleh.aldasouqi@hc.msu.edu, bill.corser@hc.msu.edu, george.abela@hc.msu.edu, SMORA@PARTNERS.ORG, \\ keren.shahar@hc.msu.edu,pk0679@gmail.com, bhattifa@msu.edu, ahsu480@gmail.com, Doctordane@gmail.com
}

How to cite this paper: Aldasouqi, S., Corser, W., Abela, G.S., Mora, S., Shahar, K., Krishnan, P., Bhatti, F., Hsu, A. and Gruenebaum, D. (2016) Fasting for Laboratory Tests Poses a High Risk of Hypoglycemia in Patients with Diabetes: A Pilot Prevalence Study in Clinical Practice. International Journal of Clinical Medicine, 7, 653-667. http://dx.doi.org/10.4236/ijcm.2016.710071

Received: July 21, 2016

Accepted: October 17, 2016

Published: October 20, 2016

Copyright (c) 2016 by authors and Scientific Research Publishing Inc. This work is licensed under the Creative Commons Attribution International License (CC BY 4.0).

http://creativecommons.org/licenses/by/4.0/

\section{(c) (i) Open Access}

\section{Abstract}

Objective: Fasting for lipid profiles is a deeply-rooted tradition that is being revisited. In patients with diabetes, such fasting poses a risk of hypoglycemia, as observed in recent studies and case reports. This iatrogenic, overlooked, form of hypoglycemia has been referred to as Fasting-Evoked En-route Hypoglycemia in Diabetes (FEEHD). The objective of the study is to determine the prevalence of FEEHD in clinical practice. Methods: A two-page survey was administered to adults with diabetes on antidiabetic medication(s). Patients were asked if they recalled having experienced hypoglycemia while fasting for laboratory tests (FEEHD) during the preceding 12 months. Results: Of 168 patients enrolled, 166 completed the survey, with a mean age of 55.3 (SD: 15.4) years. Seventy-nine (47.6\%) were females. Of these 166 patients, 119 (71 \%) had type 2 diabetes. Forty-five patients $(27.1 \%)$ reported having experienced one or more FEEHD events. Notably, only $31.1 \%$ of the patients who experienced a FEEHD event informed their provider of the event, and only $40 \%$ of FEEHD events reportedly resulted in any subsequent provider-made medication change(s) to prevent future events. Conclusions: This is the first study of FEEHD prevalence in clinical practice, the results of which serve to increase awareness amongst 
clinicians about the occurrence of FEEHD. We believe that FEEHD appears to be overlooked by clinicians. The prevalence of FEEHD in clinical practice is strikingly high (27.1\%). More concerning is the significant underreporting of FEEHD events by patients to their clinicians $(31 \%)$. We hope this study will trigger further investigation to confirm these preliminary findings and modify practice guidelines.

\section{Keywords}

Fasting, Lipids, Glucose, Hypoglycemia, Lipid Profiles, Nonfasting, FEEHD

\section{Introduction}

Lipid profiles are conceivably the most commonly used laboratory tests that traditionally require overnight fasting. Since patients with diabetes, especially type 2 diabetes mellitus (T2DM), have a high prevalence of lipid abnormalities [1], these patients expectedly undergo frequent lipid testing. Conceivably not originally based on compelling evidence, the current, deeply-rooted, practice of fasting for lipid profiles as recommended by current guidelines [2], has been recently challenged [3]-[9]. As important, there is an emerging discussion about the atherogenicity of postprandial hypertriglyceridemia, which can be missed in fasting lipid profiles [5]-[13].

In addition to the inconvenience and questionable necessity of fasting for lipid profiles in clinical practice, there is ongoing discussion regarding the safety of such fasting in patients with diabetes [7] [9]-[13]. As recently reported, patients with diabetes on hypoglycemic medications are especially vulnerable to fasting that can increase their risk for hypoglycemia especially if they are not adequately prepared for fasting [10][12]. Specifically, patients with diabetes who use insulin or sulfonylureas are put at increased risk for hypoglycemia when fasting [10]-[13]. Whereas patients who are not taking hypoglycemic medications (i.e., insulin and insulin secretagogues) are protected by a complex physiological response that inhibits insulin production by the beta cells during fasting, patients taking such medications typically do not have such a protective mechanism in view of continued circulating insulin [10]. This risk is further aggravated in patients with long-standing diabetes due to the loss of additional counter-regulatory mechanisms that protect from hypoglycemia during fasting, i.e., glucagon and catecholamines [12]-[15].

We recently described a "novel" form of hypoglycemia referred to as Fasting-Evoked En-route Hypoglycemia in Diabetes or FEEHD [9] [11]-[13]. FEEHD as defined herein is diagnosed by the following criteria: Documented hypoglycemic event (blood glucose below $70 \mathrm{mg} / \mathrm{dL}$ ) in patients with diabetes who take insulin or sulfonylurea, or both, who fast overnight for lab tests (and thus miss or delay breakfast), and who commute to the laboratory facility while fasting. The condition in a broader term can be applied to any fasting-related hypoglycemic event in patients with diabetes who are taking hypoglycemic medications (e.g., occurring at home or elsewhere). We restricted the definition in the acronym to reflect this "en-route" circumstance. This terminology, thus, high- 
lights the risk of this form of hypoglycemia that can potentially occur during driving to and from the laboratory for blood testing. This poses a significant threat given that hypoglycemia during driving has been shown to impair performance and lead to traffic accidents [16].

To our knowledge, the morbidity or mortality associated with FEEHD has not been studied, and we believe that this might be due to under recognition and under reporting [9]-[13]. However, upon more meticulous literature search, we came across one case report of laboratory-associated hypoglycemia from Thailand, which reported on a patient who died in the laboratory waiting room, while waiting for a fasting lab test [17]. She was reportedly on sulfonylurea and her blood glucose was reported as 0 (zero) $\mathrm{mg} / \mathrm{dL}$. Unlike FEEHD, however, diabetes-associated hypoglycemia and associated morbidity and mortality have been well-studied as being the "major limiting factor in diabetes management" [14] [15].

While FEEHD has been described recently in two small studies [10] [11] and a case series [12], the exact prevalence of FEEHD remains largely unknown. Thus, we hypothesized that this form of iatrogenic hypoglycemia is widely prevalent in clinical practice but judging from the dearth of reports is greatly under recognized. In this pilot study, we set out to evaluate the prevalence of FEEHD in a real life clinical setting.

\section{Materials and Methods}

This study was approved by Michigan State University's (MSU) and Sparrow Hospital's Institutional Review Boards. Informed consent was obtained from all participating patients. Patients were recruited from multiple clinics, as detailed below.

\subsection{Selection of Patients}

The study was conducted at four clinical sites: three MSU and Sparrow Hospital teaching clinics: Internal Medicine, Family Medicine and Endocrinology (Diabetes) clinics, in East Lansing and Lansing, Michigan, and The Care Free Clinic, a non-for-profit family medicine clinic for the underserved in Lansing, Michigan. The selection of the aforementioned clinics was made at random: Those were the fairly diverse set of clinics that data collectors (residents or students) happened to have access to at the time.

Inclusion criteria included adult patients who: were able to understand and answer the survey questions; had a confirmed diabetes diagnosis; and who were taking insulin and/or oral hypoglycemic agents (OHA's) or non-insulin injectable medications. Exclusion criteria included: patients who were unable to understand or complete the survey questionnaire even with assistance; patients who were not taking medications regularly; and surveys that were not completely filled.

\subsection{Study Design}

The study was conducted from October 2014 to October 2015. The research protocol consisted of a two-page written survey that was offered to patients attending the participating clinic sites. Patient inclusion and exclusion criteria were determined by data 
collectors: attendings, fellows, residents, medical students or by research-dedicated medical assistants (MA) in the clinics. Once a potentially eligible patient was identified, the MA would either complete the study enrollment using a pre-signed survey or would ask a non-MA data collector to enroll the patient.

If a participant expressed reluctance to complete the survey because of time constraints, he or she was given the option to complete the questionnaire at home and mail it to the clinic.

\subsection{Survey Questionnaire}

The survey questionnaire was designed by the study investigators. It is a simple, customized survey tool that was adapted from original questionnaires used in prior studies [10] [11], which were preliminary questionnaires intended strictly to help obtain raw information from patients to collect data in a structured manner about hypoglycemic events and circumstances thereof. The questionnaire had not been validated in prior studies, and was not intended for sophisticated larger-sample statistical analysis. Thus, the reliability of the questionnaires was not validated but was utilized in this pilot study as a facilitator in data collection.

The customized questionnaire used in this study (shown in Appendix)is a two-page simple-language survey which included, in addition to demographics and clinical info, specific questions about the number of fasting lab tests, the number of hypoglycemic events in general and the number and circumstances of FEEHD events. Hypoglycemia in patients with FEEHD was defined similar to the definition of diabetes-associated hypoglycemia in general, that is blood glucose below $70 \mathrm{mg} / \mathrm{dL}$, as defined in the literature [15]. All specific questions about hypoglycemic events were limited to the preceding 12 months. At the end of the survey, a template notification was made to instruct patients to notify their care providers of any hypoglycemic events to implement preventive measures.

\subsection{Statistical Analysis}

For this pilot study, the investigators had opted to avoid trying to conduct any pre-hoc minimal sample size calculations due to the largely unknown characteristics of the anticipated patient samples across the clinic settings. Survey questionnaires were then reviewed and entered into Excel spreadsheets and a series of cross tabulations were generated to examine for statistically significant sample subgroup differences. During Chi-square calculation and analysis of variance (ANOVA), procedures were completed with complete data sets. Variables tested to evaluate correlations with patient characteristics and the occurrence of FEEHD episode(s) included: a) clinic type (i.e., Diabetes versus other primary care clinics); b) sex; c) total number of FEEHD-associated medications taken during year; d) type of diabetes; e) duration of diabetes; f) number of reported all-cause hypoglycemic episodes during the prior year; and g) total number of fasting lab orders issued during the prior year. Finally, a series of conservative forward stepwise binary logistic regression procedures free of parametric assumptions were 
completed to examine for categorical factors and continuous covariates that were significantly associated with the occurrence of hypoglycemic episodes(s).

\section{Results}

One hundred sixty-eight patients consented to participate in the study, of whom 166 patients completed the surveys in the clinic, and 2 patients took the survey to be completed at home. After the exclusion of 2 patients who did not complete the study surveys, a final sample of 166 respondents was achieved. The mean age of patients was 55.3 years (SD 15.4), and diabetes duration averaged 16.7 years (SD 12.3). A total of 79 (47.6\%) patients were females, and 119 (71.7\%) reported having been diagnosed with T2DM (Table 1).

In regards to current medication regimen, 24 (14.7\%) reported taking one or more OHA's only; 58 (34.9\%) reported taking insulin or other injectable medications with no OHA's; and 83 (50.0\%) patients reported taking both types of medications. Patients indicated having received a mean of 2.4 (SD 21.7) fasting lab orders during the past 12 months. A total of 103 (62\%) of patients reported having experienced between one and four all-cause hypoglycemic episodes during the past year.

Table 1. Descriptive characteristics of patients and results of key questions in the study's survey questionnaire.

\begin{tabular}{|c|c|}
\hline Age, mean (SD) & $55.3(15.4)$ \\
\hline Sex, male (\%) & $87(52)$ \\
\hline Type 2 diabetes (\%) & $119(71)$ \\
\hline Duration of diabetes, mean (SD) & $16.7(12.3)$ \\
\hline Number of fasting labs reported during prior year, mean (SD) & $2.45(2.17)$ \\
\hline $\begin{array}{l}\text { Question: "Did you experience one or more reported lab-related } \\
\text { FEEHD episode during prior } 12 \text { months?" (\%) }\end{array}$ & $45(27.1)$ \\
\hline "Could you recall circumstance(s) related to FEEHD episode?" & $39(87)$ \\
\hline "Do you remember clearly advising provider of FEEHD episode?" & $14(31)$ \\
\hline "Did your FEEHD episode result in medication change?" & $18(40)$ \\
\hline $\begin{array}{l}\text { Question: "How many hypoglycemic episodes of all causes } \\
\text { have you experienced during prior } 12 \text { months?" mean (SD) }\end{array}$ & $1.52(1.60)$ \\
\hline \multicolumn{2}{|l|}{ Total number of current diabetes medications (\%) } \\
\hline OHAs only & $24(15)$ \\
\hline Insulin(s) only & $58(35)$ \\
\hline Both OHAs and insulin(s) & $83(50)$ \\
\hline Number of reported FEEHD-associated medications during prior year. mean (SD) & $1.72(0.86)$ \\
\hline
\end{tabular}


Of the 166 sample patients, $45(27.1 \%)$ patients reported having one or more labrelated FEEHD hypoglycemic events during the past 12 months. Within this sample subgroup, $39(86.7 \%)$ patients could recall at least one specific circumstance related to their FEEHD episode(s). These included (frequently overlapping) reasons such as: 1) fasting/eating less during prior night (33\%); 2) exercising (4\%); 3) recent medication changes (3\%); and 4) multiple cited reasons (19\%). Notably, only $31.1 \%$ of patients who experienced FEEHD clearly indicated that they had advised their providers of the event. Of concern as well, only $40 \%$ of FEEHD events reportedly resulted in any subsequent provider medication change(s).

Major non-significant correlations with patient characteristics and FEEHD episode(s) during prior 12 months included 1) clinic type (Pearson $\mathrm{r}=-0.069, p=0.378$ ); 2) gender $(\mathrm{r}=0.012, p=0.882)$; 3$)$ total number of FEEHD-associated medications taken ( $\mathrm{r}=0.083, p=0.292)$; and (4) total number of fasting lab orders received during prior year $(\mathrm{r}=0.000, p=0.999)$. On the other hand, patient characteristics that were significantly correlated with experiencing one or more FEEHD episode during the prior 12 months included: 1$)$ type of diabetes $(\mathrm{r}=-0.175, p=0.026) ; 2)$ duration of diabetes $(\mathrm{r}=0.173, p=0.042)$; and 3$)$ number of reported all-cause hypoglycemic episodes during the prior 12 months $(\mathrm{r}=0.305, p=<0.001)$. In summary, T2DM; diabetes duration for 11 or more years; and/or multiple all-cause hypoglycemic episodes were more likely correlated with experiencing one or more FEEHD episode(s) during the prior 12 months.

Furthermore, variables such as age category $(p=0.758)$, gender $(p=0.568)$, clinic type ( $p=0.685)$, number of prior annual fasting labs during prior 12 months ( $p=$ 0.761 ), and total number of FEEHD-associated medication(s) taken during prior year $(p=0.779$ ), each with score test statistics of $p>0.10$ were removed from later models. In the final logistic regression model, only one covariate demonstrated statistical significance: The frequency of all-cause hypoglycemic episodes during prior 12 months ( $p=$ 0.014). Of note, patients' categorical diabetes duration just barely fell out of statistical significance $(p=0.054)$. Table 2 summarizes the variables as predictors of FEEHD events.

Finally, the study was not designed to evaluate for possible association of FEEHD with factors that could influence the risk of hypoglycemia, including medications types or doses; comorbidities such as liver or kidney disease; the duration of the fasting; etc. The whole mark of the study design was the fasting itself (and skipping a meal), being iatrogenic and a known major cause of hypoglycemia in patients on hypoglycemic medications (insulin and sulphonylureas).

\section{Discussion}

This study supports the hypothesis that FEEHD occurs in clinical settings with a surprisingly high prevalence (27.1\%). To our knowledge, this is the first study to evaluate the prevalence of FEEHD in clinical practice. In our previous studies [10] [11], study designs did not allow for prevalence calculation. While we cannot necessarily extrapolate 
Table 2. Predictors of FEEHD event(s) during 12-month pre-survey period ${ }^{\star}(\mathrm{N}=166$ adult patients).

\begin{tabular}{|c|c|c|c|c|}
\hline Factor & Wald & $\operatorname{Exp}(B)$ & $95 \%$ CI & $p$ Value \\
\hline Age (Reference group $64-89$ years) ${ }^{\star *}$ & & & & 0.758 \\
\hline 19 to 50 years & & & & 0.556 \\
\hline 51 to 60 years & & & & 0.976 \\
\hline Sex (Reference group females) ${ }^{\star \star}$ & & & & 0.568 \\
\hline 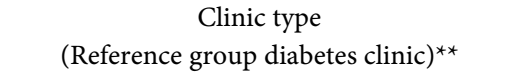 & & & & 0.685 \\
\hline Internal medicine clinic & & & & 0.424 \\
\hline Family medicine \# 1 clinic & & & & 0.296 \\
\hline Family medicine \#2 clinic & & & & 0.587 \\
\hline $\begin{array}{l}\text { Type of diabetes: } \\
(\text { reference group Type } 1)^{\star *}\end{array}$ & & & & 0.343 \\
\hline Number of annual pre-survey fasting labs ${ }^{* * *}$ & & & & 0.716 \\
\hline $\begin{array}{l}\text { Total number of FEEHD-associated } \\
\text { medications taken during prior year*** }\end{array}$ & & & & 0.779 \\
\hline $\begin{array}{l}\text { Diabetes duration in years } \\
\text { (Reference group "greater than } 20 \text { years")** }\end{array}$ & 5.824 & & & 0.054 \\
\hline 1-10 Years & 2.498 & 0.402 & $0.130-1.245$ & 0.114 \\
\hline 11-20 Years & 0.839 & 1.581 & $0.593-4.214$ & 0.048 \\
\hline $\begin{array}{l}\text { All-cause frequency of hypoglycemic } \\
\text { episodes during prior } 12 \text { months } s^{* * *}\end{array}$ & 6.053 & 1.462 & $1.080-1.978$ & $0.014^{*}$ \\
\hline
\end{tabular}

Abbreviations: FEEHD = fasting-evoked en-route hypoglycemia in diabetes; $\operatorname{Exp}(\mathrm{B})=$ the $\operatorname{Exp}(\mathrm{B})$ is equivalent to the "Odds Ratio" with numbers less than 0.500 representing less than $50 \%$ likelihood of a FEEHD occurring (e.g. the 0.402 for patients with diabetes duration of 1 - 11 years) versus more likely (e.g. patients with $11-20$ years of diabetes (1.581) - about one and a half more likely) of experiencing one or more FEEHD event(s). In other words, patients with longer history of diabetes were generally more likely to experience a FEEHD event, although not quite significantly $(p=0.054)$. ${ }^{*}$ atients may have experienced mare than one FEEHD event during 12 -month study window; ${ }^{* *}$ Categorical variable; ${ }^{* * *}$ Continuous variable.

these findings to other clinical settings, we believe that FEEHD is likely to be quite highly prevalent in clinical practice, but is perhaps under recognized. Considering 70 $\mathrm{mg} / \mathrm{dL}$ as the cut off for diabetes-associated hypoglycemia [15], the severity of hypoglycemia reported by patients who recalled the exact glucose measurement ranged from 30 to $69 \mathrm{mg} / \mathrm{dL}$. Of concern, 10 patients reported FEEHD events below $50 \mathrm{mg} / \mathrm{dL}$ and five patients reported events below $40 \mathrm{mg} / \mathrm{dL}$, with variable reported hypoglycemic symptomatology.

FEEHD is a recently recognized circumstantial category of hypoglycemia [7] [9]-[13] that is largely preventable. More concerning is that it is primarily iatrogenic. Hypoglycemia, described by Fowleras being "in many ways the Achilles heel of diabetes treatment", is the major limiting factor in diabetes management [14], with significant morbidity and mortality [15]. It is conceivable that diabetes-related hypoglycemia is a heterogeneous, multifactorial and complex condition. Multiple factors interplay to precipitate hypoglycemia in patients with diabetes, such as carbohydrate intake, medications, 
physical activity and comorbid conditions-but the common denominator is a net imbalance between medications (mainly insulin or sulfonylureas) and carbohydrate intake. The American Diabetes Association's (ADA's) practice guidelines emphasize the importance of teaching patients to balance insulin use, carbohydrate intake and exercise, adding that these strategies are not always sufficient to prevent hypoglycemia [1].

FEEHD is such a circumstance of a skipped meal that is imposed on patients by their caregiver; ordering fasting labs in patients with diabetes, without educating them to adjust their anti-diabetic medications, and to perform more glucose monitoring while fasting. More concerning, our study demonstrated that less than one-third of patients informed their clinicians about the occurrence of FEEHD and only $40 \%$ of patients had implemented strategies to prevent future FEEHD episodes. Although this iatrogenic form of hypoglycemia has been reported since 2011, currently there are no guidelines related to FEEHD [7] [9]-[13]. However, to increase awareness about FEEHD, the results of the published studies were communicated to the ADA via the online portal for public proposals suggesting the education of patients about FEEHD in the practice guidelines. As a result, in 2012 the ADA provided [18] an addendum to the thereto guidelines (2011) in the "Hypoglycemia" section [19], to include the following statement: "Patients should understand situations that increase their risk of hypoglycemia, such as fasting for tests" [18].

However, this statement would need to be implemented with various educational routes to clinical practice. Moreover, current investigators have now implemented a preventive program [11] in their clinic (attempting to streamline the fasting pre-requisite for lipid profiles, the principal lab test requiring fasting). The preventive program also implemented educational instructions for patients who are; nevertheless, requested to fast for any labs, explicitly describing medication changes and frequent glucose monitoring [11].

We had conducted a previous study after implementing the above preventive program and did a retrospective design comparing two groups of patients, one with the teaching intervention and one without. The study demonstrated a significant reduction of FEEHD in the group that received instruction prior to fasting for blood testing. Hypoglycemia was reduced by over $50 \%$ in the glucose levels of $70 \mathrm{mg} / \mathrm{dL}, 88 \%$ for 50 $\mathrm{mg} / \mathrm{dL}$ and $100 \%$ below $40 \mathrm{mg} / \mathrm{dL}$ [11].

Two major concerns regarding FEEHD need to be emphasized:

- Many patients do not have a clear understanding of hypoglycemia, and physicians do not seem to track the frequency of hypoglycemia in their patients. Thus hypoglycemia is conceivably underreported, as emphasized by Moghissi [20] and by Skarulis and Hirshberg [21] that hypoglycemic events are often underreported by patients to their clinicians.

- Diabetes-associated hypoglycemia occurring during driving has been reported to occur in $19 \%$ of T2DM in a national survey report [20]. A growing concern is emerging in regards to hypoglycemia and driving [14] [22]-[25]. The ADA's practice guidelines emphasized that "severe hypoglycemia can cause acute harm to the per- 
son with diabetes or others" [1]. Also, there is an emerging concern of litigation regarding hypoglycemia and traffic accidents [25]. Currently, we are not aware of reported cases for FEEHD occurring while driving, but there is a potential risk of this occurrence, and there is a concern of underreporting of such cases.

In parallel to this discussion, it is prudent to emphasize that in clinical practice lipid profiles are the commonest lab tests requiring fasting, including in patients with diabetes. Coincidentally, recent compelling literature has cast a doubt on the necessity of fasting for lipid profiles, altogether [3]-[13] [26]-[33] which is a stark departure from a decades-long tradition. But still, most national and international guidelines continue to recommend fasting for lipid profiles [2] [30]-[33]. This is despite the compelling evidence that fasting is not only unnecessary for lipid profiles [6] [8] [30]-[33], but in addition studies have shown that non-fasting lipid profiles are probably more relevant as predictors of cardiovascular disease [8] [26] [27]. Numerous studies have found that nonfasting lipids are not inferior to fasting, as cardiovascular disease predictors [32].

Interestingly, this deeply-rooted tradition of fasting for lipid profiles is slowly changing, however. In the US, most organizations continue to recommend fasting for lipid profiles for initial evaluation and monitoring of lipid status. However, over the last decade guidelines have evolved with more guidelines recommending that non-fasting measurement of total and high-density lipoprotein (HDL) cholesterol could be alternatively utilized, the so-called Non-HDL cholesterol [32]. Furthermore, the American Heart Association in its 2013 guidelines [32] emphasized that while the guidelines prefer fasting but fasting is not considered mandatory, nevertheless [32]. As a recent departure from the tradition of routine fasting, a recent Veterans Affairs' guideline explicitly recommended against fasting for lipid tests, except when triglycerides exceed 400 mg/dL [28]. Similarly, The Danish National Society of Clinical Biochemistry's Guidelines, now recommends non-fasting lipid profiles, with "the possibility of" ordering a fasting test if the nonfasting triglycerides level is over $350 \mathrm{mg} / \mathrm{dL}$ [29], More explicitly, Langsted and Nordestgaard (lipid experts from Denmark) recently published an editorial in the journal, Chemical Chemistry, in which they stated that "nonfasting lipid profiles are the way of the future" [30].

An entertaining example of how this issue is still being debated, at present, can be seen in a Q\&A article recently published in the journal of Clinical Chemistry [31], in which six international lipid experts were interviewed. The experts were each asked a set of questions about the issue of fasting versus nonfasting lipid testing. On the final question "Do you personally believe that nonfasting samples should be used for routine lipid profiles?", four experts said "yes" and two said "no", with diverse elaborations!

Most recently, the most powerful step towards the push for nonfasting lipid profiles, so far, has been taken by an international expert panel ( 21 experts including 3 from the US) convened by the European Atherosclerosis Society and the European Federation of Clinical Chemistry and Laboratory Medicine, which developed a joint consensus statement, simultaneously published ahead of print in two major medical journals [33]. The consensus statement, stated that "Fasting is not routinely required for determination of 
a lipid profile", and proposed cut-point values for nonfasting lipid components to be flagged by laboratories.

The primary limitations of this study include a sample size that is small; lack of exact calculation of survey response rate; data that is acquired based on patients' recollection of the hypoglycemic events and glucose measures; a survey questionnaire that did not include the type of tests for which fasting was requested. Finally, the study did not address if patients were driving themselves to and from the laboratory nor if FEEHD events caused traffic accidents. However, despite these limitations, this pilot study can serve as an initial step in bringing attention to this serious and often overlooked management problem in patients with diabetes. We suggest larger population-based studies be performed to evaluate the prevalence of FEEHD.

\section{Conclusion}

This is the first prevalence study to evaluate the prevalence of FEEHD in clinical practice. The high prevalence $(27.1 \%)$ noted in this study is quite alarming, and as alarming is the apparent unawareness of this iatrogenic problem amongst clinicians. Although this is a pilot, non-randomized study, and despite the study's limitations, it is hoped that this pilot study triggers further studies of larger samples and improved designs to address the prevalence of FEEHD in other clinical settings and in the population. Finally, it is hoped that health organizations, especially diabetes organizations, take a note of this issue and develop specific educational guidelines to prevent FEEHD.

\section{Acknowledgements}

The authors would like to thank Ms. Jinie Shirey (Department of Medicine, MSU College of Human Medicine, East Lansing, MI) for assistance with manuscript preparation; Dr. Christie Clipper (Healthy Edge, Ann Arbor, MI) for revision of the manuscript; and senior librarians Laura Smith, Michael Simmons and Steve Kalis (Sparrow Hospital, Lansing, MI) for assistance with literature search. The authors also would like to thank the clinical and support staff at all clinical sites for facilitation of the study conduction, and finally to thank all patients who participated in the study.

The study was presented in part (as interim analysis) at the 2015 annual meeting of the American Association of Clinical Endocrinologists (AACE) in Nashville, TN and the 2015 annual meeting of the American College of Physicians Michigan Chapter in Traverse City, MI. Upon study completion, a final abstract of the study was presented at the 2016 annual meeting of AACE in Orlando, FL, May 24-29, 2016. The abstract was selected by AACE to be presented as an oral presentation, as a CME activity.

\section{Author Disclosure Statement}

SA: Speaker for Janssen Pharmaceutical and Sanofi Pharmaceutical.

GA: Speaker for Merck, Amgen and Diiachi Sankyo. He served as a consultant to Kowa Pharmaceutical. He was a participant at Merck's US Thrombosis Advisory Board and Atherosclerosis Global Therapeutic Experts Forum and he has received grant support 
from Merck.

SM: Research support from Atherotech Diagnostics and NHLBI. She served as a consultant to Amgen, Quest Diagnostics, Lilly, Pfizer, and Cerenis Therapeutics.

Other co-authors: No conflict of interests.

\section{Funding}

None.

\section{Authors Contributions}

SA: Designed study; wrote/revised manuscript.

WC: Participated in study design; analyzed data; reviewed manuscript.

GA: Contributed to discussions; revised manuscript.

SM: Contributed to discussions; revised manuscript.

KS: Collected data; reviewed manuscript.

PK: Collected data; reviewed manuscript.

FB: Participated in study design; collected data; reviewed manuscript.

AH: Participated in study design; collected data; reviewed manuscript.

DG: Participated in study design; reviewed manuscript.

\section{References}

[1] The American Diabetes Association (2016) Standards of Medical Care in Diabetes-2016. Diabetes Care, 38, S1-S112.

[2] National Cholesterol Education Program (NCEP) Expert Panel on Detection, Evaluation, and Treatment of High Blood Cholesterol in Adults (Adult Treatment Panel III) (2002) Third Report of the National Cholesterol Education Program (NCEP) Expert Panel on Detection, Evaluation, and Treatment of High Blood Cholesterol in Adults (Adult Treatment Panel III) final report. Circulation, 106, 3143-3421.

[3] Grunberger, G. (2011) Do We Need a Fasting Lipid Profile to Assess Cardiovascular Risk? Journal of Diabetes, 3, 172-173. http://dx.doi.org/10.1111/j.1753-0407.2011.00141.x

[4] Gaziano, J.M. (2012) Should We Fast before We Measure Our Lipids? Archives of Internal Medicine, 172, 1705-1706. http://dx.doi.org/10.1001/jamainternmed.2013.1771

[5] Khera, A. and Mora, S. (2012) Fasting for Lipid Testing: Is It Worth the Trouble? Archives of Internal Medicine, 172, 1710-1712. http://dx.doi.org/10.1001/2013.jamainternmed.263

[6] Sidhu, D. and Naugler, C. (2012) Fasting Time and Lipid Levels in a Community-Based Population: A Cross-Sectional Study. Archives of Internal Medicine, 172, 1707-1710. http://dx.doi.org/10.1001/archinternmed.2012.3708

[7] Aldasouqi, S.A. and Grunberger, G. (2013) Is It Time to Eliminate the Need for Overnight Fasting for Lipid Tests in Patients with Diabetes? JAMA Internal Medicine, 27, 936-937. http://dx.doi.org/10.1001/jamainternmed.2013.398

[8] Doran, B., Guo, Y., Xu, J., et al. (2014) Prognostic Value of Fasting versus Nonfasting Low-Density Lipoprotein Cholesterol Levels on Long-Term Mortality: Insight from the National Health and Nutrition Survey III (NHANES-III). Circulation, 130, 546-553. http://dx.doi.org/10.1161/CIRCULATIONAHA.114.010001

[9] Aldasouqi, S. and Abela, G. (2015) Letter by Aldasouqi and Abela Regarding Article, 
"Prognostic Value of Fasting Versus Nonfasting Low-Density Lipoprotein Cholesterol Levels on Long-Term Mortality: Insight From the National Health and Nutrition Survey III (NHANES-III)”. Circulation, 131, e471. http://dx.doi.org/10.1161/CIRCULATIONAHA.114.012564

[10] Aldasouqi, S., Sheikh, A., Klosterman, P., et al. (2011) Hypoglycemia in Patients with Diabetes on Antidiabetic Medications Who Fast for Laboratory Tests. Diabetes Care, 34, e52. http://dx.doi.org/10.2337/dc10-2402

[11] Aldasouqi, S., Sheikh, A., Klosterman, P., et al. (2013) Hypoglycemia in Patients with Diabetes Who Fast for Lab Tests: A Follow up of the Cape Girardeau Hypoglycemia Prevention Program. Postgraduate Medical Journal, 125, 136-143. http://dx.doi.org/10.3810/pgm.2013.01.2629

[12] Aldasouqi, S., Gossain, V., Hebdon, M., et al. (2012) Causes of Fasting-Evoked Hypoglycemia in Diabetes (FEEHD): A Case Series. International Journal of Clinical Medicine, 3, 751757. http://dx.doi.org/10.4236/ijcm.2012.37A132

[13] Aldasouqi, S. and Grunberger, G. (2014) The Traditions and Risks of Fasting for Lipid Profiles in Patients with Diabetes. Postgraduate Medicine Journal, 126, 98-107. http://dx.doi.org/10.3810/pgm.2014.11.2837

[14] Fowler, M.J. (2011) The Diabetes Treatment Trap: Hypoglycemia. Clinical Diabetes, 29, 3639. http://dx.doi.org/10.2337/diaclin.29.1.36

[15] Workshop on Hypoglycemia, American Diabetes Association (2005) Defining and Reporting Hypoglycemia in Diabetes: A Report from the American Diabetes Association Workgroup on Hypoglycemia. Diabetes Care, 28, 1245-1249. http://dx.doi.org/10.2337/diacare.28.5.1245

[16] Pedersen-Bjergaard, U., Færch, L., Allingbjerg, M.L., Agesen, R. and Thorsteinsson, B. (2015) The Influence of New European Union Driver's License Legislation on Reporting of Severe Hypoglycemia by Patients with Type 1 Diabetes. Diabetes Care, 38, 29-33. http://dx.doi.org/10.2337/dc14-1417

[17] Wiwanitkit, V. (2004) Case of Sudden Death in Venipuncture Clinic. Phlebotomy, 19, 193. http://dx.doi.org/10.1258/0268355042554993

[18] The American Diabetes Association (2012) Standards of Medical Care in Diabetes-2012. Diabetes Care, 35, S11-S63. http://dx.doi.org/10.2337/dc12-s011

[19] The American Diabetes Association (2011) Standards of Medical Care in Diabetes-2011. Diabetes Care, 34, S11-S61. http://dx.doi.org/10.2337/dc11-s011

[20] Foster M. (2011) Survey Reveals Low Hypoglycemia Awareness among Patients with Diabetes. Endocrine Today.

http://www.healio.com/endocrinology/diabetes/news/print/endocrine-today/\%7Be3d5b9ab -65d9-4796-890b-3b69df497be4\%7D/survey-reveals-low-hypoglycemia-awareness-amongpatients-with-diabetes

[21] Skarulis, M.C. and Hirshberg, B. (2004) Hypoglycemia in the Adult. In: LeRoith, D., Taylor, S.I. and Olefsky, J.M., Eds., Diabetes Mellitus. A Fundamental and Clinical Text, 3rd Edition, Lippincott Williams \& Wilkins, Philadelphia, 1427-1438.

[22] Frier, B.M. (2000) Hypoglycemia and Driving Performance. Diabetes Care, 23, 148-149. http://dx.doi.org/10.2337/diacare.23.2.148

[23] Cox, D.J., Gonder-Frederick, L.A., Kovatchev, B.P., Julian, D.M. and Clarke, W.L. (2000) Progressive Hypoglycemia's Impact on Driving Simulation Performance: Occurrence, Awareness and Correction. Diabetes Care, 23, 163-170. http://dx.doi.org/10.2337/diacare.23.2.163 
[24] The American Diabetes Association (2016) 8. Cardiovascular Disease and Risk Management. Diabetes Care, 39, S60-S71. http://dx.doi.org/10.2337/dc16-S011

[25] Tan, S.Y. (2012) Law and Medicine: Physician Liability in Driving Accidents. Clinical Endocrinology News.

http://www.clinicalendocrinologynews.com/views/law-medicine/blog/physician-liability-in -driving-accidents/f94a86515778e327464be37b744698dd.html

[26] Bansal, S., Buring, J.E., Rifai, N., et al. (2007) Fasting Compared with Nonfasting Triglycerides and Risk of Cardiovascular Events in Women. JAMA, 298, 309-316.

http://dx.doi.org/10.1001/jama.298.3.309

[27] Langsted, A., Freiberg, J.J., Tybjaerg-Hansen, A., Schnohr, P., Jensen, G.B. and Nordestgaard, B.G. (2011) Nonfasting Cholesterol and Triglycerides and Association with Risk of Myocardial Infarction and Total Mortality: The Copenhagen City Heart Study with 31 Years of Follow-Up. Journal of Internal Medicine, 270, 65-75. http://dx.doi.org/10.1111/j.1365-2796.2010.02333.x

[28] Downs, J.R. and O'Maley, P.G. (2015) Management of Dyslipidemia for Cardiovascular Risk Reduction: Synopsis of the 2014 US Department of Veterans Affairs and US Department of Defense Clinical Practice Guideline. Annals of Internal Medicine, 163, 291-297. http://dx.doi.org/10.7326/M15-0840

[29] Nordestgaard, B.G. and Varbo, A. (2014) Triglycerides and Cardiovascular Disease. Lancet, 384, 626-635. http://dx.doi.org/10.1016/S0140-6736(14)61177-6

[30] Langsted, A. and Nordestgaard, B. (2015) Nonfasting Lipid Profiles: The Way of the Future. Clinical Chemistry, 61, 1123-1125. http://dx.doi.org/10.1373/clinchem.2015.243139

[31] Rifai, N., Young, I., Nordestgaard, B., Wierzbicki, A., et al. (2016) Nonfasting Sample for the Determination of Routine Lipid Profile: Is It an Idea Whose Time Has Come? Clinical Chemistry, 62, 428-435. http://dx.doi.org/10.1373/clinchem.2015.247866

[32] Mora, S. (2016) Nonfasting for Routine Lipid Testing: From Evidence to Action. JAMA Internal Medicine, 176, 1005-1006. http://dx.doi.org/10.1001/jamainternmed.2016.1979

[33] Nordestgaard, B.G., Langsted, A., Mora, S., et al. (2016) Fasting Is Not Routinely Required for Determination of a Lipid Profile: Clinical and Laboratory Implications Including Flagging at Desirable Concentration Cut-Points-A Joint Consensus Statement from the European Atherosclerosis Society and European Federation of Clinical Chemistry and Laboratory Medicine. European Heart Journal, 37, 1944-1958.

http://dx.doi.org/10.1093/eurheartj/ehw152 


\section{Appendix}

IRB-approved Survey Questionnaire, Page 1:

\section{Fasting-Evoked En-Route Hypoglycemia in Diabetes (FEEHD)}

Patient Name:

Date of Birth:

Diabetes: Yes

If yes: Type 1
Sex: M F

Tel:

Age: $\quad$ years

In the past 1 year, have you had a hypoglycemic (blood sugar less than 70) event while fasting for a laboratory blood draw? (Such as a cholesterol test)

Yes

No

Do you remember how low your sugar was? If yes, what was it:

Medications at the time of the hypoglycemic event:

Insulin Pump

Insulin Injections

Diabetic Tablets (Orals/OHAs)

Insulin: Lantus

Levemir

Novolog

Humalog

Apidra

$\mathrm{NPH}$

$50 / 50$

$70 / 30$

$75 / 25$

Regular Byetta

Bydureon Victoza Symlin

OHAs: Glipizide(Glucotrol) Glyburide(Diabeta) Glimeperide(Amaryl) pioglitazone(Actos) rosiglitazone(Avandia) Nateglinide(Starlix) repaglinide(Prandin) colesevelam(Welchol)

Sitagliptin(Januvia) linagliptin(Tradjenta) alogliptin(Nesina) saxagliptin(Onglyza)

Metformin(Glucophage/Fortamet/Glumetza) dapagliflozin(Farxiga) canagliflozin(Invokana) miglitol(Glyset) acarbose(Precose) Other:

Do you recall what your sugar was the night before, and the morning of the test? If yes, approximately what range: Low High Average

Did you make changes on your diabetic medications the night before, or the morning of the test? If yes, what changes, and were they suggested by your physician:

Did you feel the low sugar? If so, what did you feel, and what did you do: 


\section{IRB-approved Survey Questionnaire, Page 2:}

In the past 1 year, have you had other hypoglycemic (blood sugar less than 70) events at all? If so, how frequently?

Never Once Several Times Monthly Weekly Near Daily

What were the circumstances of the hypoglycemic event/s?

Fasting Forgot to eat Ate less than expected Post exercise

Recent medication changes (within the past week) Other:

Did you make your provider aware of your hypoglycemic episode/s? If yes, was your diabetic medications regimen changed, and if so how:

If your diabetic regimen has been changed after hypoglycemic episode/s, how has this changed the frequency of your hypoglycemic episodes:

No change Less frequent, if so how much: More frequent, if so how much:

Never Once Several Times Monthly Weekly Near Daily

To the best of your knowledge, how many times have you had fasting labs drawn in the past year?

How many times have the results of these labs resulted in changes to your therapy (medical regimen)?

Thank you for helping us to better understand, hypoglycemic events in diabetic patients, and what we may be able to do to minimize them!

Please notify your primary doctor or diabetes specialist if you have experienced any low sugars that they are not aware of, so changes in diabetes management can be made to avoid low sugars. 
Submit or recommend next manuscript to SCIRP and we will provide best service for you:

Accepting pre-submission inquiries through Email, Facebook, LinkedIn, Twitter, etc. A wide selection of journals (inclusive of 9 subjects, more than 200 journals)

Providing 24-hour high-quality service

User-friendly online submission system

Fair and swift peer-review system

Efficient typesetting and proofreading procedure

Display of the result of downloads and visits, as well as the number of cited articles

Maximum dissemination of your research work

Submit your manuscript at: http://papersubmission.scirp.org/

Or contactijcm@scirp.org 